Revista Mídia e Cotidiano

Artigo Seção Livre

Volume 11, Número 1, abril de 2017

Submetido em: 17/03/2017

Aprovado em: 28/04/2017

\title{
BOTAFOGO E O CANAL 100: documentário e o ethos de memórias no jornalismo esportivo
}

\section{BOTAFOGO AND CANAL 100: documentary and the ethos of memories in sports journalism}

\author{
Rafael Duarte Oliveira VENANCIO ${ }^{1}$; Isabel Cristina de Oliveira GONÇALVES ${ }^{2}$
}

Resumo: O Botafogo Football Club foi fundado em 1904 no Rio de Janeiro e, em 1942, fundiu-se com o Club de Regatas Botafogo, para criar o Botafogo de Futebol e Regatas. A instituição figura entre os mais importantes clubes de futebol do Brasil e, de acordo com a FIFA, está entre os 20 principais clubes de futebol do século XX. Ao longo de seus 113 anos de existência, diversas coberturas jornalísticas preencheram de emoções e informações aqueles que têm alguma ligação com a agremiação ou se interessam pelo esporte em geral. Esse material, produzido por jornalistas, apresenta um discurso específico e corrobora determinada construção de imagem do futebol. Desse modo, a presente pesquisa tem como objetivo analisar de que forma os documentários, tidos como materiais comunicacionais perenes, representam e constroem a memória do Botafogo de Futebol e Regatas, evidenciando os principais aspectos reforçados pelos documentaristas/jornalistas para produzir uma imagem específica do clube. Tendo como base a Análise do Discurso de linha francesa e os conceitos de ethos-prévio e ethosdiscursivo, a produção audiovisual analisada foi "Glorioso Botafogo" realizada pelo pioneiro veículo audiovisual de jornalismo esportivo, Canal 100. O resultado final dessa averiguação denota que ambas reforçam uma imagem pré-estabelecida, associando a equipe a uma aura mística, ao caráter de sofrimento e a sua importância histórica para a consolidação do futebol brasileiro.

Palavras-chave: Botafogo de Futebol e Regatas; Canal 100; Memória; Jornalismo esportivo.

Abstract: Botafogo de Futebol e Regatas was founded in 1904 in Rio de Janeiro and is one of the most important football clubs in Brazil. Throughout its 110 years of existence, several journalistic coverages have been made in the attempt to bring information to those who have some connection with the team or are interested in the sport in general. These materials produced by journalists present a specific discourse and corroborate for a certain image construction of the club. Thus, the present research aims to analyse how

1 Doutor em Meios e Processos Audiovisuais pela Universidade de São Paulo (2013). Professor Adjunto, nível C1 da Universidade Federal de Uberlândia. E-mail: rdovenancio@gmail.com.

2 Bacharel em Comunicação Social: Habilitação em Jornalismo pela Universidade Federal de Uberlândia (2015). E-mail: isabeloligoncalves@hotmail.com. 
the documentaries, considered as perennial communication materials, represent and build the memory of Botafogo de Futebol e Regatas, evidencing the main aspects reinforced by documentary filmmakers / journalists in order to produce an image specific club. Based on the analysis of the French Speech Discourse and the concepts of previousethos and discursive-ethos, the audio-visual production analysed was "Glorioso Botafogo" produced by the pioneering vehicle of sports journalism, Canal 100, and the final result of this investigation denotes that both reinforce a pre-established image, associating the team with a mystical aura, the character of suffering and its historical importance for the consolidation of Brazilian soccer.

Keywords: Botafogo de Futebol e Regatas; Canal 100; Memory; Sports Journalism.

\section{Introdução}

Sou um menino de rua perdido na dramaticidade existencial da poesia; pois o Botafogo é um menino de rua perdido na poética dramaticidade do futebol. Paulo Mendes Campos, cronista e redator principal do Canal 100, extraído do livro "O gol é necessário”, Record, 2000

Ídolos são quase sempre incorporados às reportagens, crônicas esportivas e, principalmente, documentários sobre o Botafogo. Os jornalistas usam esses personagens conhecidos pela torcida botafoguense, como Garrincha, Didi, Nilton Santos, Amarildo, Quarentinha, Gérson, Heleno de Freitas e Zagallo, na tentativa de respaldar o próprio texto, explicitar uma imagem específica. Em 2015, o time não viveu uma de suas melhores fases, já que foi rebaixado para segunda divisão do Campeonato Brasileiro em 2014 e convivia com uma dívida estimada em R $\$ 750$ milhões de reais. Paulo Cézar Caju, bicampeão carioca (1967/68), campeão da Taça-Brasil com o Botafogo em 1968 e campeão mundial na Copa de 1970, no México, é o personagem principal de uma matéria produzida pelo canal televisivo SporTV e divulgada pelo site do grupo para opinar sobre a diretoria atual, comissão técnica e demais contratações.

Não acredito nessa diretoria que foi eleita agora. Dois dirigentes que entraram agora faziam parte do grupo do Maurício (Assumpção). Além disso, na minha opinião, o 
Botafogo continua retrocedendo. Isso não pode com o Antônio Lopes e René Simões. Eles não têm identificação com o nosso clube (ÍDOLO, 2015, s. n.).

Já Nilton Santos, um dos laterais mais famosos da história do futebol e ícone da equipe carioca, voltou aos jornais em 2015 devido ao Estádio Olímpico, conhecido como Engenhão, inaugurado pela Prefeitura do Rio de Janeiro em 2007 e arrendado pelo Botafogo. Falecido em 2013, o jogador construiu sua carreira atuando exclusivamente pelo clube e pela Seleção Brasileira. Ao todo, foram 17 anos com a camisa alvinegra. Em janeiro de 2017, a Prefeitura do Rio de Janeiro reconheceu oficialmente a mudança do nome para Estádio Olímpico Nilton Santos.

Dois anos depois de o ex-prefeito Eduardo Paes homologar o pedido protocolado pelo Botafogo autorizando a usar o termo fantasia, agora o nome é oficial. O atual prefeito do Rio de Janeiro, Marcelo Crivella, rebatizou o então chamado Estádio Olímpico João Havelange na última sexta-feira, e a mudança foi publicada no Diário Oficial do município nesta segunda. (AGORA, 2017, s. n.).

O longo jejum de títulos importantes também colabora para que os jornalistas busquem uma representação em suas matérias baseadas nas conquistas remotas. No anseio de que os botafoguenses se sintam atraídos pelo que produzem, encontram modos de relacionar os assuntos atuais aos ídolos do passado. Essas produções jornalísticas atuam diretamente na preservação memorial do Botafogo, clube de futebol criado em 1904 e que faz parte dos mais tradicionais do Brasil.

\section{Objetivo, Método e Corpus}

A pesquisa ${ }^{3}$ teve como objetivo analisar de que forma os documentários, tidos como materiais comunicacionais perenes, representam e constroem a memória do Botafogo de Futebol e Regatas. Figurando entres os 20 clubes de futebol do país com maior número de torcedores, o Botafogo faz parte de uma ala tradicional no meio esportivo (PESQUISA, 2014, s. n.). A elaboração de material comunicacional apoiada em glórias passadas foi um

\footnotetext{
3 O presente artigo é baseado em partes do Trabalho de Conclusão de Curso intitulado "Botafogo: a Representação e a Construção Da Memória Do Clube Através De Documentários" desenvolvido e orientado pelos autores, respectivamente.
} 
fator determinante para o desenvolvimento desse estudo especifico sobre construção de imagem e memória.

Nossa escolha foi por um documentário, "O Glorioso Botafogo", produzido por Carlos Niemayer em 1995. A obra faz parte do material veiculado pelo Canal 100, cinejornal que teve duração de 1959 a 2000, sendo exibido semanalmente até 1986, e depois realizando produções esporádicas (HISTÓRIA, 2014a, s. n). O documentário do Canal 100 tem 40 minutos de duração, alternando imagens do elenco botafoguense em campo, com depoimentos de torcedores anônimos e ilustres. Os títulos da década de 1960 e 1990 são o enfoque deste material.

Tendo como especialidade documentários cinematográficos voltados para o futebol, o Canal 100 garantiu a conservação de um acervo a respeito deste esporte a partir da década de 1950 no Brasil. O cinejornal era exibido nos cinemas antes dos longasmetragens, mesclando informação e visão documental com um viés narrativo ${ }^{4}$ A produtora de Carlos Niemayer teve como auge as décadas de 1960 e 1970, quando a cobertura esportiva ainda não tinha tanto destaque na televisão brasileira (HISTÓRIA, 2014a, s. n).

Como suporte para a elaboração deste estudo, foi realizada uma revisão bibliográfica acerca da história do Botafogo, englobando o site oficial, páginas desenvolvidas por torcedores e matérias publicadas em jornais digitais. As informações contidas na obra "Botafogo - Entre o céu e o inferno", escrita por Sérgio Augusto (2005), foram tomadas como base de comparação em relação às veiculadas no documentário citado. A biografia oficial traz dados históricos e depoimentos de personagens ligados a construção da memória do clube carioca.

Estudos sobre a Análise de Discurso de linha francesa, desenvolvidos por Dominique Maingueneau (1987, apud BRANDÃO, 2004), Helena Brandão (2009) e Eni Puccinelli Orlandi (2009), também foram empregados nesta pesquisa como base teórica, assim como algumas características que retomam a filosofia de linguagem, proposta por

\footnotetext{
4 É importante notar que os cinejornais eram obrigatórios nos cinemas brasileiros antes da exibição dos filmes desde o Governo Vargas nos anos 1940 enquanto estratégia de propaganda oficial. Mesmo após o fim do Estado Novo, esta prática se manteve.
} 
Bakhtin (1995 apud MELO; GOMES; MORAIS, 2001). Já a definição de documentário explanada por Bill Nichols (2005) serviu como base teórica para a classificação do material selecionado. As características explicadas permitiram entender o processo de representação desenvolvido nos vídeos.

O conceito de ethos, apontado por Maingueneua (2011) e Amossy (2005), corroboraram a averiguação proposta neste estudo. A noção de ethos prévio e ethos discursivo foi aplicada na análise do processo de representação do Botafogo.

A conceituação de memória e documento, explicitada por Le Goff (1990) também foi utilizada na análise. O documentário foi estudado como recorte da realidade, tendo como base a proposta do escritor francês. Mesmo apresentando informações reais sobre o clube (documentos oficiais), eles se configuram através do olhar de quem os produziu e utilizam os dados (histórias, imagens, áudios) em um contexto escolhido, arquitetado.

A pesquisa teve caráter descritivo documental de laboratório. Seguindo um modelo adotado por Silva e Venancio (2014), a descrição do documentário de forma narrativa configura-se como um estudo de caso. Essa descrição narrativa consiste em evidenciar a estrutura imagética, textual e discursiva adotada pelo documentarista. De forma cronológica, as principais informações do documentário foram elencadas e descritas, e posteriormente, analisadas.

Reiterando Silveira e Córdova (2009, p. 33-34), o trabalho se apresenta como uma pesquisa básica, a qual utiliza conceitos pré-estabelecidos, mas que, de mesma forma, contribui para o desenvolvimento da ciência, gerando novos conhecimentos e auxiliando a difusão da área proposta. Além disso, pode ser definida como qualitativa, já que, mesmo trazendo dados numéricos, o intuito é explicitar traços subjetivos da análise. Entende-se também que esse estudo adquire forma de levantamento, baseando-se na observação do vídeo.

\section{Descrição narrativa de "O Glorioso Botafogo"}

"O Glorioso Botafogo", produzido pelo Canal 100, se configura, com base nos estudos de Nichols (2005, p. 26), como um documentário de representação social. A organização proposta pelo documentarista mostra uma realidade com a qual muitos 
indivíduos já estão familiarizados, no caso, torcer por um time de futebol, frequentar estádios, eleger ídolos no meio esportivo. A intervenção se dá pela escolha específica pelo Botafogo, pelos personagens expostos e pelas edições, como cortes e seleção das trilhas sonoras.

O documentário começa com uma mescla de imagens produzidas em duas diferentes épocas da história do clube. Dribles e gols de jogadores que compunham os elencos de 1962 e 1995 são exibidos ao som do hino do clube. A música composta por Lamartine Babo em 1942, não se trata do hino oficial ${ }^{5}$, mas se popularizou entre os torcedores e é tido como o cântico mais importante do Botafogo.

Em sequência, durante entrevista, um dos líderes da Torcida Jovem do Botafogo, tradicional torcida organizada, exalta a atuação de Carlos Augusto Saade Montenegro, presidente do clube carioca de 1994 a 1996. Montenegro, que também está na arquibancada, ao lado da torcida, agradece o trabalho do então técnico da campanha de 1995, Paulo Autuori, e afirma ter fé na conquista do Campeonato Brasileiro. Ambas as declarações são acompanhadas pelo coro da torcida ao fundo, que entoa o hino supracitado.

Um dos torcedores mais conhecidos do Botafogo, o ator e político Stepan Nercessian, assegura que o título de 1995 será conquistado e que a presença de integrantes da equipe do Canal 100 traz sorte para o clube. $O$ ator relembra a infância vivida no estado de Goiás, reiterando a importância das imagens de futebol veiculadas pela produtora em seus cinejornais para o desenvolvimento de seu amor pela equipe carioca. Em sequência, um torcedor comum fala sobre a saudade que sente de ver Garrincha em campo.

A presença de um narrador é inserida aos seis minutos de duração. Interposta às imagens da final do Campeonato Carioca de 1962 (Botafogo 3 x 0 Flamengo), a voz narra os principais lances da partida e comenta a presença massiva da torcida no Maracanã. A inserção de um comentário voz de Deus, ou seja, um orador que é ouvido, mas não

\footnotetext{
5 O Botafogo possui dois hinos oficiais, sendo um relativo ao remo e outro ao futebol. O primeiro foi composto por Alberto Ruiz e o segundo tem letra de Octacílio Gomes e música de Eduardo Souto. Lamartine Babo, famoso por desenvolver marchinhas de Carnaval, compôs canções para os seis grandes clubes do futebol carioca: América, Bangu, Botafogo, Flamengo, Fluminense e Vasco. Contudo, foi essa versão não-oficial que se tornou o hino mais conhecido do alvinegro (HINOS, 2014, s. n.).
} 
exposto, reitera o caráter de documentário expositivo, como proposto por Nichols (2005, p. 143). Por utilizar o mundo histórico como matéria-prima, mas adotar ferramentas para transformá-lo e enfatizar qualidades poéticas, faz com que o mesmo também se enquadre no estilo poético (NICHOLS, 2005, p. 141).

Marcador dos dois primeiros gols da partida, o ponta-direita Garrincha é adjetivado como "incontrolável” e "imarcável”. O terceiro e último gol da partida foi marcado contra pelo lateral rubro-negro Vanderlei. O goleiro botafoguense Manga também é exaltado na narração, ganhando o apelido de parede.

O narrador chama o elenco de 1962 de "time de craques", que apresentava um futebol da melhor qualidade. A final é intitulada como "encontro de gigantes". Recorrese à frase "a sorte também jogava em favor dos botafoguenses", já que muitas jogadas de gol do Flamengo acabaram na trave. O narrador enfatiza que o estilo de jogar em conjunto, a presença de Garrincha e de uma torcida incentivadora não poderiam render nada menos que o título.

Um corte seco, característica que se repete durante todo o documentário, introduz novamente o ex-presidente do clube Carlos Augusto Montenegro. Ele conta que se tornou botafoguense por causa de Garrincha. O torcedor já exposto anteriormente também volta a falar do craque, definindo-o como a "alegria do povo" e como "o Brasil". A sua volta, na rampa de acesso ao Maracanã, jovens e adultos gritam o nome do clube carioca.

Novamente temos a inserção do narrador, que reproduz um texto de Nelson Rodrigues, "Os que negam Garrincha" (1966). Publicado originalmente pelo jornal $O$ Globo (02/05/1966), foi reproduzido no livro “À sombra das chuteiras imortais” (1993). Abaixo, parte da crônica narrada no documentário:

Vocês se lembram de Charlie Chaplin, em Luzes da ribalta, fazendo o número das pulgas amestradas? Pois bem, Mané deu-nos um alto momento chapliniano. E o efeito foi uma bomba. Na primeira bola que recebeu, já o povo começou a rir. Aí é que está o milagre: - o povo ria antes da jogada, da graça, da pirueta. Ria adivinhando que Garrincha ia fazer a sua grande ária, como na ópera. Como se sabe, só o jogador medíocre faz futebol de primeira. O craque, o virtuose, o estilista, prende a bola. Sim, ele cultiva a bola como uma orquídea de luxo. Foi uma das jogadas mais histriônicas de toda a vida 
de Mané. Primeiro, pulou por cima da bola. Fez que ia, mas não foi. Pula pra lá, pra cá, com a delirante agilidade de 58. [...] Em 58, ou 62, o mais indigente dos brasileiros pôde tecer a sua fantasia de onipotência. E, por tudo isso, as multidões, sem que ninguém pedisse, e sem que ninguém lembrasse, as massas derrubaram os portões. E ofereceram a Mané Garrincha uma festa de amor, como não houve igual, nunca, assim na terra como no céu (RODRIGUES, 1993, p. 134).

Como ilustração, as cenas exibem o ponta-direita atuando pelo Botafogo e pela Seleção Brasileira, além da população comemorando a conquista da Copa do Mundo em 1962.

De volta a 1995, um repórter do Canal 100 entrevista torcedores no Maracanã. Um define o alvinegro como "o melhor time do mundo". Outro, acompanhado pelos filhos, também botafoguenses, diz que os elencos de 1967 e 1968 foram os melhores que ele já vira. São gravações de 1967 que dão continuidade ao documentário. A partida final entre Botafogo e América consagraria o campeão da Taça Guanabara. Já sem os grandes ídolos que compuseram o time no início da década de 1960, a equipe conseguiu uma vitória por 3 a 2, com gols de dois jogadores que também se tornariam futuros ícones: Jairzinho e Paulo Cezar Caju. O narrador exalta a nova formação do Botafogo e afirma que ambos os times representavam a força jovem no futebol do estado.

A descrição da final do Carioca de 1967 é antecedida por botafoguenses imitando radialistas, fingindo narrar gols de Túlio Maravilha no Brasileirão de 1995. Retomando imagens de arquivo, são exibidas as mais de 100 mil pessoas que compareceram ao Maracanã para ver o jogo contra o Bangu. A apreensão de todos é evidenciada nas filmagens. Roberto abriu o placar para o Botafogo, mas Mário empatou para o Bangu. Gerson, que para Sérgio Augusto (2005, p. 198) teria sido o dono do espetáculo, marcou o gol do título alvinegro e impediu o bicampeonato do rival.

Após a jogada de Gerson, a torcida começa a cantar "Está Chegando a Hora", versão da canção mexicana "Cielito Lindo", gravada por Carmen Costa. A música é tida como um clássico no meio futebolístico, entoada por torcidas que já vislumbram a vitória antes mesmo do apito final. A volta olímpica do elenco campeão é ilustrada ao som do hino do clube. 
Sucessivamente, mostra-se um grupo cantando o hino no Maracanã. O som das vozes vai-se mesclando ao som da música oficial. Já exibindo imagens da partida contra o Vasco da Gama, válido pela final do Campeonato Carioca de 1968, é inserido um depoimento em áudio de Salim Simão, jornalista botafoguense e amigo íntimo de Nelson Rodrigues. Ele diz que o futebol só aceita o Botafogo, inclusive quando se trata da Seleção Brasileira, referindo-se ao alto número de jogadores do clube carioca nas campanhas em que o país foi campeão mundial. Os quatro gols marcados pelo alvinegro sacramentaram o bicampeonato carioca. O time é classificado pelo narrador como perfeito.

O repórter do Canal 100 volta a entrevistar torcedores no ano de 1995, indagando sobre seus conhecimentos a respeito de jogos passados. Torcedores recordam a final da Taça Guanabara de 1968. O jogo contra o Flamengo é descrito como difícil. Um pênalti batido errado pelo botafoguense Gerson e a reviravolta no segundo tempo faz com que o texto frise que os jogos do Botafogo são sempre carregados de dramaticidade. A partida termina com o placar de 4 a 1 para o alvinegro, vencendo a competição por dois anos consecutivos.

Os torcedores voltam a ser ouvidos no Maracanã em 1995. Dessa vez, citam a sorte e o destino. Dois afirmam que não, mas tem a certeza de que o clube será campeão nacional. Outros quatro respondem que sim, que a sorte está a favor do Botafogo e que aquele seria um ano destinado para a vitória. $\mathrm{O}$ jornalista pergunta a um homem sobre a opinião a respeito da retomada da sede de General Severiano ${ }^{6}$. Ele afirma que era o momento esperado por cada botafoguense, que só dessa maneira eles se sentiam completos novamente e que o lugar trazia boas vibrações para o clube. O mesmo torcedor é perguntado sobre qual era o seu elenco preferido e, elencando os jogadores, escolhe a equipe de 1948. São reiterados também o presidente do clube na época, Carlito Rocha, e

\footnotetext{
$6 \quad$ O Estádio General Severiano, que pertencia ao Botafogo, foi inaugurado em 1913. Era no local que a equipe mandava seus jogos. Em 1927, foi construído no mesmo terreno o Palacete Colonial como sede do clube. As estruturas foram vendidas para a Companhia do Vale do Rio Doce em 1976. Em 1994, o Botafogo retomou a posse da área, e iniciou um processo de reforma do Casarão, que se configura como um patrimônio tombado pelo governo do Rio de Janeiro. O Estádio foi demolido ainda na década de 1970. Atualmente o local abriga um centro esportivo, loja oficial, restaurante, sala de troféus e um memorial alvinegro (SEDES, 2014, s. n.).
} 
a mascote Biriba, marcados na história do Botafogo pela relação de sorte e pelas superstições.

Então, começam a ser mostradas imagens da final do Campeonato Carioca de 1948. Novamente uma crônica de Nelson Rodrigues é narrada. Dessa vez, ela trata da relação da aura mística adotada pelos botafoguenses ao longo dos anos. O texto "O Deus de Carlito Rocha" foi escrito em 1958, sendo veiculado pelo jornal Manchete Esportiva (04/01/1958). Ele faz referência direta à sua crença fervorosa em Deus e na sorte. Para o cronista, é por causa de um místico arsenal implementado por Carlito, que o Botafogo conseguiu naquele ano realizar partidas esmagadoras para que a campanha fosse irretocável. Para Nelson Rodrigues, é em função da presença de Carlito Rocha na história do clube que o Botafogo desenvolveu uma relação intrínseca com o sobrenatural.

Adiante, o trecho da crônica "O Deus de Carlito Rocha" (1958), retirada do livro “À sombra das chuteiras imortais" (1993), utilizada pelo Canal 100:

Eu imagino que, até o dia da batalha, tenham dito o diabo do velho Rocha. Riam dele, de alto a baixo. Pobres de nós, que não sabemos respeitar as grandes paixões! E ninguém queria perceber o que era óbvio: - graças a Carlito, criava-se uma relação entre o Botafogo e o sobrenatural, e o clássico decisivo passava a adquirir um pouco de eternidade (RODRIGUES, 1993, p. 43).

$\mathrm{Na}$ sequência, um botafoguense responde a uma pergunta do jornalista do Canal 100 sobre o técnico Paulo Autuori, que dirigiu a equipe em 1995. Ele afirma que a presença do comandante garante consistência tática à equipe. Outro torcedor afirma que tem muita fé no trabalho realizado. Uma declaração do treinador confirma a ideia segundo a qual o futebol deve ser simples e primar pela eficiência.

Em entrevista no gramado, o jogador Túlio Maravilha afirma que se caso fizesse um gol na partida a comemoração faria referência ao movimento "Reage Rio"7 . A partir daí, o documentário passa a exibir gols marcados pelo atacante alvinegro durante o Campeonato Brasileiro de 1995, no qual o time se sagraria campeão. Túlio foi o artilheiro

\footnotetext{
7 Manifestação organizada pela Organização Não Governamental (ONG) Viva Rio, em novembro de 1995, e tinha como objetivo contestar a insegurança na capital carioca. A cidade enfrentava uma onda de sequestros e o tráfico de drogas se consolidava nas favelas (REAGE, 2014, s. n.).
} 
da competição, com 23 gols. Depois, são mostradas cenas da final do campeonato disputada contra a equipe paulista Santos Futebol Clube, que terminou com o placar em 1 a 1. Imagens do Maracanã lotado e o som da torcida cantando o hino de Lamartine Babo em coro encerram o documentário.

A aparição do repórter repetidas vezes, segundo Nichols (2005, p. 153), se caracteriza como um recurso dos documentários participativos. Constrói-se uma interação explícita entre a equipe que produz o documentário e a comunidade botafoguense. Portanto, compreende-se que o documentário do Canal 100 pode ser caracterizado como expositivo, poético e participativo.

\section{Construção discursiva do ethos do Botafogo}

"O Glorioso Botafogo" aborda períodos específicos da história do clube carioca. As campanhas realizadas nas décadas de 1940, 1960 e 1990 são apresentadas através de arquivos configurados dentro de uma narrativa. O documentário segue uma linha ideológica proposta pelo Canal 100 em suas demais produções, atuando na preservação de documentos e da memória do futebol. Durante as narrações e entrevistas, é adotado um linguajar típico do cenário jornalístico esportivo. Expressões como "gol de placa", "artilheiro nato", “tirar de letra" e "na pequena área" são utilizadas para reiterar os jogos, sendo conhecidas pelos aficionados do futebol.

Este recurso de linguagem diz respeito ao que Brandão (2009, p. 4) denomina como contexto, dentro dos preceitos que Maingueneua (apud BRANDÃO, 2004) propõe na Análise do Discurso de linha francesa. É uma maneira de angariar a empatia de quem se interessa pelo assunto e garantir uma interpretação específica da realidade apresentada. Metáforas adotadas no vídeo, como "o Botafogo massacrou o Vasco da Gama”, surgem como sugestão de imagem. Como apresentado no referencial teórico construído nesta pesquisa, segundo Gomis (1991, p. 65, apud MELO; GOMES; MORAIS, 2001, p. 6), para que o espectador desenvolva sentimentos por algo não vivenciado recorre-se à construção de uma imagem mental, sendo essa fruto do uso desse tipo de recurso linguístico. Muitas pessoas podem não ter visto a partida na época, então, essa sugestão de imagem é bem-vinda. 
É nítida a construção de um dialogismo produzido pelo Canal 100. As declarações dos entrevistados, a presença do narrador em certos momentos e as crônicas de Nelson Rodrigues lidas se configuram como "vozes" do discurso proposto no documentário. Esses diálogos caracterizam o que Bakhtin (1995 apud MELO; GOMES; MORAIS, 2001, p. 7) define como polifonia. As falas do documentário compactuam entre si e defendem uma imagem do clube. A forma como o Botafogo e seus jogadores são representados através das imagens e discursos reforça alguns ethos. Por diversas vezes a expressão "sorte" é empregada pelos personagens. A ligação dos botafoguenses com assuntos sobrenaturais, evidenciado também por Sérgio Augusto (2004, p. 146), ajuda na construção de um ethos de superstição. Já a dificuldade encontrada nas decisões de títulos, explicitada com as narrações, reafirma um caráter de aflição, também exposto por Sérgio Augusto (2004, p. 43). O longo período sem títulos expressivos é exposto no documentário e reforça esse ethos de sofrimento.

Por fim, compreende-se que os jogadores da equipe de 1995 são comparados aos que atuaram pelo time de 1940 a 1965. O talento, as jogadas, os gols são narrados e reiterados pelos torcedores, fazendo referência aos ídolos do passado. A comunicação relativa ao Botafogo e expressa nesse documentário sustenta-se com base na construção de memória, nas glórias do passado. A imagem do clube, mesmo após décadas, ainda está ligada a jogadores como Garrincha, ao estilo de jogo adotado na década de 1960.

\section{Considerações Finais}

A pesquisa teve como intento analisar de que modo o documentário do Canal 100 representa o Botafogo e o papel da produção audiovisual para a manutenção de uma estruturação ideológica sobre o clube. De forma qualitativa, os discursos adotados foram descritos, assim como a construção imagética de cada um, a fim de entender quais características botafoguenses eram reforçadas.

Os conceitos de ethos-prévio e ethos-discursivo, elaborados por Maingueneau (2011, p. 13), foram fundamentais para entender essa representação. As falas reforçam que o alvinegro ainda se sustenta com as conquistas e ídolos da década de 1960. Reiteram que, por diversas vezes, o caráter místico foi utilizado para que os jogadores tivessem 
confiança na vitória. Essa aura de superstição - potencializada por Carlito Rocha, exatleta e dirigente do clube nos anos 40 - pretende traduzir o sentimento da torcida, que se apega a questões religiosas para tentar incentivar o time. A sorte, ou a falta dela, com os infortúnios improváveis, são em todo momento enfatizados na narrativa descrita. A famosa frase "Tem coisas que só acontecem ao Botafogo" (extraída do artigo "Botafogo e eu") é do cronista Paulo Mendes Campos, principal redator do Canal 100.

Personagens expostos nos vídeos, tanto botafoguenses, como torcedores e jogadores de outros clubes, realçam a importância do Botafogo para que o futebol brasileiro ganhasse destaque mundial. O talento de jogadores alvinegros como Garrincha, Nilton Santos, Amarildo, Gerson, entre outros, auxiliou a Seleção Brasileira a conquistar três títulos mundiais. Produções como a do Canal 100 ajudam a sustentar a mística segundo a qual, apesar do jejum de títulos nacionais expressivos e com a enorme dívida financeira, o clube figura entre os mais importantes do país.

\section{Referências}

AGORA é oficial: Nilton Santos substitui o nome João Havelange no Engenhão. 2017. GloboEsporte.com. Disponível em: $<$ http://globoesporte.globo.com/futebol/times/botafogo/noticia/2017/02/agora-e-oficial-niltonsantos-substitui-o-nome-joao-havelange-no-engenhao.html>. Acesso em: 2 mai. 2017.

AMOSSY, Ruth. Da noção retórica de ethos à análise do discurso. In: AMOSSY, Ruth (Org.). Imagens de si no discurso: a construção do ethos. São Paulo: Contexto, 2005, 207p.

AUGUSTO, Sérgio. Botafogo: entre o céu e o inferno. 2. ed. Rio de Janeiro: Ediouro, 2004, 255 p.

BRANDÃO, Helena H. N. Analisando o discurso. 2009. Museu da língua portuguesa: Estação da Luz. Disponível em: <http://www.museudalinguaportuguesa.org.br/files/mlp/texto_1.pdf>. Acesso em: 15 mai. 2014.

BRANDÃO, Helena H. N. Introdução à Análise do discurso. 2. ed. rev. Campinas, SP: Editora da Unicamp, 2004.

CAMPOS, Paulo Mendes. O gol é necessário. São Paulo: Record, 2000.

CLUBES que mais cederam jogadores à Seleção em Copas. 2014. Eu Vivo esporte. Disponível em: $\quad<$ https://www.euvivoesporte.com.br/esportes/futebol/top5/clubes-que-mais-cederamjogadores-a-seleao-em-copas-34>. Acesso em: 01 jun. 2014.

COPA 2014: calçada da Fama do Maracanã espera museu do estádio. 2014. Agência Estado. Disponível em: <http://m.futebolinterior.com.br/futebol/Copa-2014/noticias/201407/Maracana:-Calcada-da-Fama-do-Maraca-espera-museu>. Acesso em: 8 dez. 2014. 
FILME sobre a vida de Nilton Santos, "Ídolo" terá estreia no Festival do Rio. 2014. In: GloboEsporte.com. Disponível em: $<$ http://globoesporte.globo.com/futebol/noticia/2014/09/filme-sobre-vida-de-nilton-santosidolo-tera-estreia-no-festival-do-rio.html>. Acesso em: 25 nov. 2014.

GERHARDT, T. SILVEIRA, Denise. (Org.). Métodos da pesquisa. Porto Alegre: UFRGS, 2009, pp. 33-34.

HADDAD, Galit. Ethos-prévio e ethos discursivo: o exemplo de Romain Rolland. In: AMOSSY, Ruth (Org.). Imagens de si no discurso: a construção do ethos. São Paulo: Contexto, 2005, 207 p.

HEINE, P. V. B. O ethos e a intimidade regulada: especificidades da construção da construção do ethos no processo de revelação da intimidade no blogs pessoais. Dissertação de Mestrado. Salvador, Instituto de Letras UFBA, 2007. Disponível em: $<$ http://www.bibliotecadigital.ufba.br/tde_busca/arquivo.php?codArquivo=1469>. Acesso em: 28 jun. 2014.

HINOS: conheça nossos cantos. 2014. BotafogoFr. Disponível em: $<$ http://www.botafogo.com.br/hinos.php?cat=oclube $>$. Acesso em: 10 nov. 2014.

HISTÓRIA. 2014. BotafogoFR. Disponível em: $<$ http://www.botafogo.com.br/historia.php?cat=oclube $>$. Acesso em: 08 out. 2014.

HISTÓRIA. 2014a. Canal 100. Disponível em: <http://www.canal100.com.br/home/historia>. Acesso em: 03 set. 2014.

ÍDOLO do Bota, Caju critica diretoria e contratações de René e Lopes. 2015. SporTV.com. Disponível em: <http://sportv.globo.com/site/programas/sportv-news/noticia/2015/01/idolo-dobota-caju-critica-diretoria-e-contratacoes-de-rene-e-lopes.html>. Acesso em: 14 jan. 2015.

ÍDOLOS. 2014. BotafogoFR. Disponível em: $<$ http://www.botafogo.com.br/idolos.php?cat=oclube>. Acesso em: 15 out. 2014.

LE GOFF, Jacques. História e memória. Tradução de Irene Ferreira, Bernardo Leitão, Suzana Ferreira Borges. 5. ed. Campinas, SP: UNICAMP, 1990, 553 p.

MAIA, Aline Silva Correa; OLIVEIRA, Roberta. Futebol, Identidade e Memória: o Lance! do Consumo do Botafogo de 1962. Logos: Comunicação e Universidade, Rio de Janeiro, v. 17, n. 02, p.151-163, jun. 2010.

MARQUES, Bruno; GONÇALVES, Igor; QUINTELLA, Thiago. Copa: Botafogo segue líder entre clubes que mais cederam jogadores à Seleção. 2014. GloboEsporte.com. Disponível em: $<$ http://globoesporte.globo.com/blogs/especial-blog/numerologos/post/copa-botafogo-seguelider-entre-clubes-que-mais-cederam-jogadores-selecao.html>. Acesso em: 07 maio 2014.

MELO, Cristina Teixeira V. de; GOMES, Isaltina Mello; MORAIS, Wilma. O Documentário como Gênero Jornalístico Televisivo. XXIV Congresso Brasileiro de Comunicação, 2001, Campo Grande. Mato Grosso do Sul: Intercom, 2001. Disponível em: $<$ http://www.portcom.intercom.org.br/pdfs/e969053bfccdc7be14f5e0a009b95215.pdf >. Acesso em: 15 nov. 2014.

MAINGUNEAU, Dominique. A propósito do ethos. In: MOTA, Ana Raquel; SALGADO, Luciana (Org.). Ethos discursivo. 2. ed. São Paulo: Contexto, 2011, 264 p. 
NEVES, Milton. Que fim levou?: Heleno de Freitas. 2014. Terceiro Tempo. Disponível em: $<$ http://terceirotempo.bol.uol.com.br/que-fim-levou/heleno-de-freitas-912>. Acesso em: 15 nov. 2014.

NICHOLS, Bill. Introdução ao Documentário. Trad. Mônica Saddy Martins. Campinas, SP: Papirus, 2005.

ORLANDI, Eni Puccinelli. O que é linguística. 2. ed. São Paulo: Brasiliense, 2009, 74 p.

PARA pagar dívida de R 750 milhões, Botafogo precisa juntar arrecadação de cinco anos. 2014. ESPN. Disponível em: <http://espn.uol.com.br/noticia/464647_para-pagar-divida-de-r-750milhoes-botafogo-precisa-juntar-arrecadacao-de-cinco-anos>. Acesso em: 02 dez. 2014.

PESQUISA LANCE! Ibope: Flamengo segue com a maior torcida do Brasil. 2014. LANCE!NET. Disponível em: <http://www.lancenet.com.br/minuto/Pesquisa-LANCE-IbopeFlamengo-Brasil_0_1200480135.html>. Acesso em: 20 dez. 2014.

PORTO, Roberto. Qual a mais expressiva frase? 2007. O blog do Roberto Porto. Disponível em: <http://portoroberto.blog.uol.com.br/arch2007-03-11_2007-03-17.html>. Acesso em: 25 maio 2014 .

QUEM Somos. 2014. ESPN. Disponível em: <http://espn.uol.com.br/quemsomos>. Acesso em: $10 \mathrm{dez} .2014$

REAGE, Rio. 2014. Jornal O Globo. Disponível em: $<$ http://memoria.oglobo.globo.com/jornalismo/primeiras-paginas/reage-rio-8952703>. Acesso em: 15 dez. 2014.

RECONHECIMENTO de alguns títulos do futebol mundial. Campões do Futebol. 2014. Disponível em: $<$ http://www.campeoesdofutebol.com.br/titulos_reconhecidos.html $>$. Acesso em: 15 out. 2014.

RIZEK, André; MENESES, Eduardo de; RIBEIRO, Flavia. Lelé da Cuca. Placar. Rio de Janeiro, v. 2, n. 1322 , set. 2008 , pp. 49-51.

RODRIGUES, Nelson. O Deus de Carlito Rocha. In: CASTRO, Ruy (org.). À sombra das chuteiras imortais: crônicas de futebol. São Paulo: Companhia das Letras, 1993.

RODRIGUES, Nelson. Os que negam garrincha. In: CASTRO, Ruy (org.). À sombra das chuteiras imortais: crônicas de futebol. São Paulo: Companhia das Letras, 1993.

SEDES. 2014. BotafogoFR. Disponível em: < http://www.botafogo.com.br/sedes.php?cat=oclube>. Acesso em: 08 out. 2014.

SILVA, Fernanda Torquato Braga; VENANCIO, Rafael Duarte Oliveira. Tons de Cora: ficção no Documentário Biográfico. XXXVII Congresso Brasileiro de Comunicação, 2014, Foz do Iguaçu. Paraná: Intercom, 2014. Disponível em:< http://www.intercom.org.br/sis/2014/resumos/R9-1752-1.pdf>. Acesso em: 20 out. 2014.

SILVEIRA, D. CORDOVA, F. A pesquisa científica. In: GERHARDT, T. SILVEIRA, D. (Org). Métodos da pesquisa. Porto Alegre: UFRGS, 2009.

TEIXEIRA, André. Botafogo de Futebol e Superstições. 2009. Última divisão. Disponível em: $<$ http://www.ultimadivisao.com.br/botafogo-de-futebol-e-supersticoes/>. Acesso em: 01 jun. 2014. 
TÍTULOS: Nossas conquistas. 2014. BotafogoFR. Disponível em: $<$ http://www.botafogo.com.br/titulos_interna.php?cat=futebol>. Acesso em: 10 maio 2014.

VALE, Luna. Cerca de $300 \mathrm{~kg}$ e 2,5 metros de altura. Veja as imagens da estátua de Garrincha. 2010. Esporte Espetacular. Disponível em: $<$ http://globoesporte.globo.com/Esportes/Noticias/Esporte_Espetacular/0,,MUL145582116321,00.html>. Acesso em: 08 dez. 2014. 